\title{
The mucopolysacchari- doses and anaesthesia: a report of clinical experience
}

Patients with the mucopolysoccharidoses show widespread, progressive involvement and derangement of many organs and tissues which can have profourd implications for the anaesthetist. These disorders are uncommon and few anaesthetists care for these patients an a regular basis although individual patients often undergo multiple anaesthetics for procedures intended to improve their quality of life. There is a relarive paucity of literature dealing with clinical anaesthetic experience with these patients. We report a retrospective review of she recent experience at the Children's Hospital of Eastern Ontario in Otrawa, Canada, administering 38 anaesthetics to nime patients with several of the mucopolysaccharidoses; specifically the Huter, Hurler, Sanfilippo and Morquio syndromes. The establishment and maintenance of an adequate airway represents the most commonly encountered anaesthetic-related probiem in these patients. We found an overall incidence of ainway-related problems of 26 per cent. In patients with the Hurler or Hunter sydromes the incidence of airway-related problems was 53 per cent.

\section{Key words}

GENETIC FACTORS: mucopolysaccharidoses; ANAESTHESIA: paediatric; COMPLICATIONS: airway, tracheal intubation.

From the Deparment of Anaesthesia, Queen's University, Kingston, Ontario and the Department of Anaesthesia, Children's Hospital of Eastern Ontario (EJR), University of Ottawa, Ottawa, Ontario.

Address correspondence to: Dr. Ian A. Herrick, Department of Anaesthesia, Kingston General Hospital, Kingston, Ontario K7L 2V7.
The mucopolysaccharidoses represent a group of hereditary disorders resulting from defects in the degradation of mucopolysaccharides present ubiquitously in connective tissue. Failure of degradation, due to lysosomal enzyme deficiencies, leads to accumulation of incompletely catabolized mucopolysaccharides in connective tissue throughout the body especially bone, brain, liver, blood vessels, skin, cartilage, airways, heart valves and cornea.

There are seven recognized syndromes which are classified eponymously. Table I summarizes the main clinical features associated with each syndrome. The specific biochemical and physical characteristics of each syndrome are well described ${ }^{1,2}$

The diagnosis of specific syndromes is based primarily on clinical features and is supported by laboratory tests based on the excretion pattern of mucopolysaccharide degradation products present in the urine of affected individuals and/or assays for specific enzyme deficiencies. Ten specific lysosomal enzyme deficiences have been demonstrated and assays, conducted on leukacytes or cultured fibroblasts, are available in specialized laboratories to aid in confirmation of the diagnosis.

A numeric classification system (Table l) has evolved which attempts to categorize the syndromes according to both the clinical features and the demonstrated enzyme deficiencies. This system remains confusing, however, due to apparent inconsistences in our understanding of how the enzyme deficiencies correlate with specific clinical features. For example, some of the numeric classes (Type III A-D) share identical clinical features but have different enzyme deficiencies, while other numeric classes (Type I H, HS, S) share an identical enzyme deficiency but demonstrate distinctly different clinical features.

In this report, the eponym based system of classification has been used to identify the individual disorders that collectively constitute the mucopolysaccharidoses. This system currently represents the classification that is utilized most extensively in the literature and is recognised most readily by the clinician, including the anaesthetist.

The mucopolysaccharidoses are recessively inherited. The Hunter syndrome is x-linked; the others are autoso- 
TABLE I Mucopolysaccharidoses: summary of clinical features

\begin{tabular}{|c|c|c|c|}
\hline \multicolumn{2}{|l|}{ Syndrome } & \multirow[b]{2}{*}{ Incidence* } & \multirow[b]{2}{*}{ Clinical features } \\
\hline Type & Eponym & & \\
\hline $\mathrm{I}(\mathrm{H})$ & Hurler & $1 / 100,000$ & $\begin{array}{l}\text { Severe progressive involvcment of heart, } \\
\text { skeleton and airways. Progressive mental } \\
\text { retardation. Possible cervival spine involvement. }\end{array}$ \\
\hline $\mathbf{I}(\mathbf{S})$ & Scheie & $1 / 500,000$ & $\begin{array}{l}\text { Mild, slowly progrcssiwe skeletal and } \\
\text { airway inwolvement. Cardiac valve involvement } \\
\text { common. Usually intellectually nomal. }\end{array}$ \\
\hline I(HS) & Hurler/Scheie & $1 / 115,000$ & $\begin{array}{l}\text { Intermediate involvernent. Mental retardation. } \\
\text { Micrognathia common. }\end{array}$ \\
\hline Il & Hunter & $\begin{array}{l}1 / 70,000 \\
1 / 150,000\end{array}$ & $\begin{array}{l}\text { Wide range - mild to severe forms. Usually } \\
\text { more slowly progressive than } \mathrm{I}(\mathrm{H}) \text {. } \\
\text { Intelligence may be normal in mild forms. }\end{array}$ \\
\hline $\begin{array}{l}\text { III } \\
(A \text { to } D)\end{array}$ & Sanfilippo & $\begin{array}{l}\text { possibly as } \\
\text { high as } \\
1 / 24,000\end{array}$ & $\begin{array}{l}\text { Progressive severe mental retardation. Milder, } \\
\text { slowly progressive somatic involvement. Several } \\
\text { enzyme deficiencics, identical clinical features. }\end{array}$ \\
\hline IV $(A, B)$ & Morquio & very rare & $\begin{array}{l}\text { Mild and severe forms. Prominent skeletsl } \\
\text { involvement usually leads to pulmonary } \\
\text { compromise. Aortic valve involvement common. } \\
\text { Very high incidence of odontoid hypoplasia. } \\
\text { Ustally intelleetually nonnal. }\end{array}$ \\
\hline$v$ & No longer used - & erly Scheie sy & \\
\hline VI & Maroteaux-Lamy & very rare & $\begin{array}{l}\text { Variable severity of somatic involvement. } \\
\text { Slower progression than } \mathrm{I}(\mathrm{H}) \text {. Usually } \\
\text { intellectually normal. Possible cervical spine } \\
\text { involvement. }\end{array}$ \\
\hline
\end{tabular}

"Based on estimates reported by McKusick and Neufeld. '

mal. All the mucopolysaccharidoses are progressive in nature, the severity of involvement thus increasing with age. The Hurler syndrome, considered the prototypical mucopolysaccharidosis, is characterized by the most rapid progression, usually leading to death before ten years of age. No definitive therapy is available.

Thete are diverse potential problems faced by the anaesthetist caring for these patients in the perioperative period. These include a predisposition to problems with upper airway obstruction due to mucopolysaccharide infiltration of the lips, tongue, epiglottis, tonsils and adenoids. Obstructive and restrictive ventilatory defects result from abnormal laryngeal and tracheal cartilage, copious airway secretions and skeletal deformities involving the vertebrae and thorax. Craniofacial abnormalities, stiffening of the temperomandibular joints and an anteriorly positioned larynx complicate laryngoscopy and intubation. Infiitration of cardiac structures leads to valvular heart disease, cardiomyopathy and coronary artery disease. Heart failure is commonly associated with the terminal stages of these syndromes. Pulmonary hypertension may complicate chronic respiratory obstruction. Progressive mental retardation is associated with several of the mucopolysaccharidoses and may be complicated by communicating hydrocephalus. Involvement of the cervical spine may result from odontoid hypoplasia and potential atlanto-axial subluxation or from infiltration of the spinal meninges and subsequent compression of the cervical spinal cord (pachymeningitis cervicalis ${ }^{1}$ ).

The purpose of this report is to present and discuss our recent clinical experience providing anaesthetic care for nine children with mucopolysaccharidoses who collectively underwent 38 operative or diagnostic procedures at the Children's Hospital of Eastern Ontario.

\section{Report of anaesthetic experience}

\section{Methods}

The medical records of all patients with a diagnosis of a mucopolysaccharidosis admitted to the Children's Hospital of Eastem Ontario from January 1979 to August 1986 were retrieved. Those patients who underwent anaesthe- 
sia during this period were identified and their diagnoses, operative procedures, anaesthetic management and perioperative courses were revicwed retrospectively.

\section{Results}

A total of 13 patients were identified. One patient with an equivocal diagnosis of a mucopolysaccharidosis and conflicting urine test results was cxcluded from further consideration.

Of the 12 remaining patients, one child had been previously diagnosed at another paediatric hospital. Laboratory records (urine excretion patterns and/or enzyme assay results) supporting the clinical diagnoses were available for the other 11 patients, including all patients who underwent anaesthesia. Three children died during the period reviewed. Autopsy results confirmed the diagnosis in each of these cases.

Of the 12 patients reviewed, nine patients were identified with diagnoses which included the Hurler, Hunter, Sanfilippo and Morquio syndromes, who underwent a total of 38 anaesthetics for a variety of surgical or diagnostic procedures as outlined in Table II. No patients

TABLE II Summary of anacsthetics administered distributed according to syndrome and the type of operative procedurc

\begin{tabular}{|c|c|c|}
\hline Syndrome & $\begin{array}{l}\text { Number of } \\
\text { parients }\end{array}$ & $\begin{array}{l}\text { Number of } \\
\text { anaesthetics }\end{array}$ \\
\hline Hurler & 3 & 13 \\
\hline Hunter & 2 & 6 \\
\hline Sanfilippo & 3 & 16 \\
\hline Morquio & 1 & 3 \\
\hline Scheie & 0 & 0 \\
\hline Hurter/Scheie & 0 & 0 \\
\hline \multirow[t]{2}{*}{ Maroteaux-Lamy } & 0 & 0 \\
\hline & - & - \\
\hline Total & 9 & 38 \\
\hline \multicolumn{2}{|l|}{ Type of procedure } & $\begin{array}{l}\text { Number of } \\
\text { anaesthetics }\end{array}$ \\
\hline \multicolumn{2}{|l|}{ ENT } & 14 \\
\hline \multicolumn{2}{|l|}{ Hernia repair } & 5 \\
\hline \multicolumn{2}{|c|}{ Orthopaedic } & 4 \\
\hline \multicolumn{2}{|c|}{ Orthopaedic and hemia } & 2 \\
\hline \multicolumn{2}{|c|}{ Diagnostic studies } & 6 \\
\hline \multicolumn{2}{|c|}{ Lumbo-peritoneal shunt } & 1 \\
\hline \multicolumn{2}{|c|}{ Dental } & 1 \\
\hline \multicolumn{2}{|c|}{ Hydrocoele } & 1 \\
\hline \multicolumn{2}{|c|}{$I$ and $D$ (Haematoma) } & 1 \\
\hline \multicolumn{2}{|c|}{ Esophagoscopy } & 1 \\
\hline \multicolumn{2}{|l|}{ Tracheostomy } & 1 \\
\hline \multirow{3}{*}{\multicolumn{2}{|c|}{ Gastrostomy }} & 1 \\
\hline & & - \\
\hline & & 38 \\
\hline
\end{tabular}

TABLE III Distribution of types of induction

\begin{tabular}{lll}
\hline Type of induction & $\begin{array}{l}\text { Number of } \\
\text { anaesthetics }\end{array}$ & $\begin{array}{l}\text { Number of } \\
\text { intubation }\end{array}$ \\
\hline Intraverous & 21 & 16 \\
$\begin{array}{l}\text { Inhalation } \\
\text { Inhalation with }\end{array}$ & 12 & 11 \\
$\quad$ ETT in sutu* & 2 & - \\
$\quad$ Tracheostomy in situ* & 1 & - \\
Other: & & \\
Local infiltration plus & 1 & 0 \\
$\quad \mathrm{~N}_{2} \mathrm{O} \mathrm{O}_{2}+$ diazepam & 1 & 0 \\
IM ketamine & - & 27 \\
& 38 & \\
\hline
\end{tabular}

*Endotracheal tube (ETT) or tracheostomy in place at the time of induction of anaesthesia.

Frequency of intubation $=27 / 35=77 \%$.

with the Scheie, Hurler/Scheie or Maroteaux-Lamy syndromes were identified.

The incidence of intraoperative problems was assessed based on the anaesthesia record, which includes specific sections for entry of intraoperative complications and documentation of the ease of intubation, as well as a survey of the operative record. Postoperative complications were assessed based on the Recovery Room record, comments related to postoperative care recorded by the Recovery Room nursing staff and a survey of the postoperative progress notes.

Table III outlines the distribution of various induction techniques utilized and the frequency with which endotracheal intubation was performed. Clearly, there was a predominance of intravenous inductions, with or without associated intubation. The majority of intravenous inductions were conducted in the younger patients and in patients with the Sanfilippo syndrome, that is, in those patients with a lesser degree of somatic involvement. In most of the older patients with more advanced disease, inhalation inductions were favoured in anticipation of potential difficulty maintaining the airway and/or difficult intubation. Thiopentone was used as the intravenous induction agent.

Tracheal intubation was performed during 77 per cent (27/35) of the anaesthetics administered, excluding three anaesthetics administered to a patient with an endotracheal tube or tracheostomy in place at the time of induction. Each of the nine patients reported in this series was intubated in relation to the administration of anaesthesia at some point during the time period reviewed, although clearly not all of the anaesthetics administered to individual patients necessarily involved intubation.

Table IV presents the data on the syndrome-related incidence of airway problems encountered in these 
patients. Problems with intubation reflect the incidence of difficult intubations as reported on the anaesthesia record. Problems with the airway include all reported problems encountered managing the airway such as excessive secretions, ease of obstruction as well as problems with intubation as reported in the anaesthetic, operative or Recovery Room record. Problems related to intubation and airway maintenance were noted exclusively in patients with the Hurler or Hunter syndromes.

Table $\mathrm{V}$ shows the incidence of airway problems and the incidence of difficult intubations related to age. Since most of these patients underwent several procedures under anaesthesia at various ages, individual patients could be included in more than onc age group. An increasing incidence of airway problems with increasing age was not demonstrated.

Of note in Tables III, IV and V are three anaesthetics administered to one patient with the Hurler syndrome who had an endotracheal tube or tracheostomy in place at the time of induction. This patient had been admitted to hospital and was subsequently intubated, with considerable difficulty, in the intensive care unit due to a respiratory arrest associated with advanced airway involvement and preumonia. These three anaesthetics are considered separately in the data related to the frequency of intubation (Table III). They are excluded from the data on problems related to intubation but included in the data on problems associated with airway management (e.g., excessive secretions, etc.) in Tables (V and V. Other anaesthetics administered to this patient were included in the pooled data.

With the exception of two procedures, all operative or diagnostic procedures were performed under general anacsthesia utilizing a potent inhalation agent, usually halothane. One of the two exceptions (Table III) was a diagnostic shudy performed on a patient with the Sanfilippo syndrome in which intramuscular ketamine was used as the induction and maintenance agent. The second exception was a gastrostomy performed under local infiltration on a patient with advanced Sanfilippo syndrome who received nitrous oxide, oxygen and small intravenous doses of diazepam for intraoperative sedation. Preoperatively this patient had a history of dysphagia and recurrent problems with aspiration. One week postoperatively this child experienced a respiratory arrest and died. No specific problems had been documented in the immediate (48 hour) perioperative period. Other anaesthetics administered to these two patients are included in the pooled data in Table III. All anaesthetics administered to these two paticnts are included in the data in Tables IV and $V$.

Two other patients, one with the Hurler syndrome and one with the Hunter syndrome, died of respiratory and/or carciac failure related to the terminal stages of their disease. Both deaths occurred in the Children's Hospital of Eastern Ontario during the period reviewed in this report. Neither death was temporally or causally related to the administration of anaesthesia.

\section{Discussion}

Consistent with the widespread connective tissue involvement characteristic of these disorders, the data shows a predominance of ENT, orthopaedic and hemiorrhaphy procedures performed on these patients (Table II). Anaesthetics administered for these procedures constituted 66 per cent of the total experience in this series.

The most common anaesthesia related problem encountered in these patients relates to the establishment and maintenance of an adequate airway in the perioperative period. An overall incidence of perioperative problems associated with the airway of 26 per cent and an overall incidence of problem intubation of 11 per cent was found (Table IV). Of particular interest is the fact that all

TABLE IV Syndrome-related incidence of ainway problems

\begin{tabular}{|c|c|c|c|c|c|}
\hline Syndrome & $\begin{array}{l}\text { Number of } \\
\text { patients }\end{array}$ & $\begin{array}{l}\text { Nottiber of } \\
\text { anaesthetics }\end{array}$ & $\begin{array}{l}\text { Number of } \\
\text { intubarions }\end{array}$ & $\begin{array}{l}\text { Number of } \\
\text { prablems with } \\
\text { intubarion }\end{array}$ & $\begin{array}{l}\text { Total number } \\
\text { of airway } \\
\text { problems }\end{array}$ \\
\hline Hurler & 3 & 13 & $10+3$ in silu* & I (10\%) & $7(54 \%)$ \\
\hline Hunter & 2 & 6 & 4 & $2(50 \%)$ & $3(50 \%)$ \\
\hline Sanfilippo & 3 & 16 & 12 & $0(0 \%)$ & $0(0 \%)$ \\
\hline \multirow[t]{3}{*}{ Morquio } & 1 & 3 & $\mathbf{l}$ & $0(0 \%)$ & $0(0 \%)$ \\
\hline & - & - & - & $\longrightarrow$ & $\longrightarrow$ \\
\hline & 9 & 38 & 27 & $3(11 \%)$ & $10(26 \%)$ \\
\hline
\end{tabular}

Hunter/Hurler syndromes alone:

Intubation problems $=3 / 14=21 \%$.

Total airway problems $=10 / 19=53 \%$.

"Endotracheal tube or trachexstony in place al the time of induction. These cases not included in data on problems with intubation but included in data on problems with airway. 
TAELE $V$ Age-related incidence of airway problems

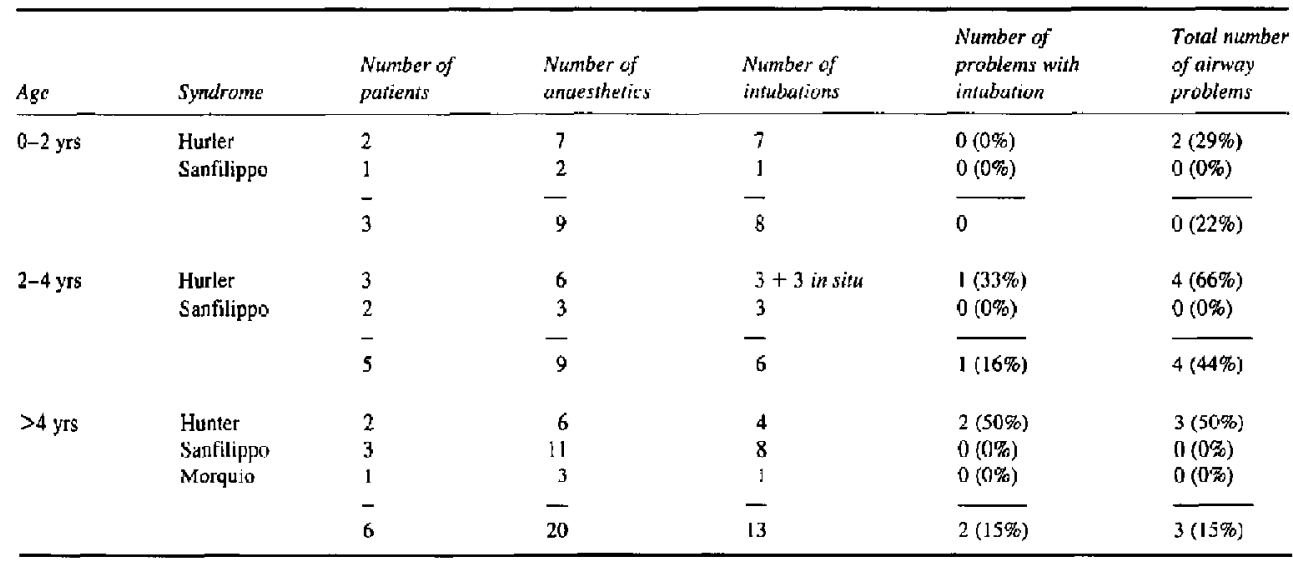

*Individual patients undergoing more than one procedure at different ages may be included in more than one age group.

reported airway problems occurred in the patients with the Hurler or Hunter syndromes. When these patients were considered separately the incidence of airway problems, and of problem intubations, increased dramatically to 53 and 21 per cent respectively (Table IV). No cuses of failed intubation were reported. The absence of documented airway problems in patients with the Sanfilippo syndrome is consistent with other published series. Both Kempthome and Brown ${ }^{3}$ and Baines and Keneally ${ }^{4}$ report experience with patients with the Sanfilippo syndrome. The latter study also reported no documented difficult airways in these patients and the former study reported problematic intubations only at an age (11 years old) that exceeded the age range (eight years old) seen in this series.

There were no reported perioperative arrhythmias or related cardiac events in this series. Three of the patients had documented cardiac valve involvement and one patient had cardiomegaly secondary to cardiomyopathy. Collectively, these four patients underwent a total of ten of the 38 anaesthetics reported. Although there are reports of cardiorespiratory arrests associated with difficult or failed intubations in these patients, ${ }^{3-5}$ none of the recent reports of anaesthesia experience have documented perioperative problems of a purely cardiac origin precipitated by the administration of anaesthesia. ${ }^{3,4,6}$

Young and Harper, $"$ in a study delineating the clinical features of a mild form of the Hunter syndrome, reported "serious problems," including one death, during attemped intubations in four of their cases. These authors also reported one paticnt who died due to "cardiac arrest during surgery"; however, the spccific details surrounding these events were not included. Overall, cardiac disease was found to be the most common cause of death in this study of 31 patients.

Brosius and Roberts ${ }^{7}$ reported finding severe coronary artery narrowing in each of six patients with the Hurler syndrome studied at necropsy. Interestingly however, these authors found that despite severe coronary artery involvement, none of the six patients had symptoms of cardiac dysfunction or evidence of myocardial ischaemia during life. Furthermore, necropsy evidence of myocardial ischaemia was found in only one of the six patients and this consisted of a small subendocardial scar.

Although the incidence of coronary artery and cardiac valvular involvement is reportedly high in these patients, $1,3,5,7$ the contribution of cardiac involvement in these patients to their tolerance of stress related to airway problems and/or anaesthesia is not well established.

The data on the age-related incidence of airway problems in these patients does not demonstrate a progressive increase in incidence with increasing age, although this might be expected based on the progressive nature of these disorders (Table V). The data is, however, skewed by the distribution of patients with the Hurler and Hunter syndromes into distinctly different age categories and the predominance of anaesthetics administered to patients with the Sanfilippo syndrome in the older age group ( $>4$ years). No airway problems were encountered in the Sanfilippo syndrome patients presumably due to the milder and more slowly progressive nature of somatic involvement characteristic of this syndrome, as discussed above. The data published by Baines and Keneally also failed to demonstrate a higher incidence of airway problems related to age. 
With regard to induction techniques in these patients, the data do not suggest a significant advantage of intravenous versus inhalation techniques in the younger patients with minimal of mild somatic involvement. Younger patients with advanced somatic involvement and a marked potential for upper airway obstruction are good candidates for inhalation induction. The potential to maintain spontaneous ventilation until the ability to adequately assist ventilation manually can be established is mandatory, and the ability to use a high inspired oxygen concentration is of equal import.

The choice of induction technique in older patients with significant somatic involvement is more difficult. In this series the two patients with the Hunter syndrome were reported to have developed problems during induction associated with anaesthetics administered at ages seven and nine years respectively. Both patients were reported to be mentally retarded and uncooperative preoperatively. Attempted inhalation inductions were tolerated poorly. As a result, the anaesthetist in each case reported switching to an intravenous induction technique utilizing thiopentone and succinylcholine. Problems maintaining the airway, compounded by difficult intubations, were subsequently experienced. Although both patients were ultimately intubated successfully, both inhalation and intravenous induction techniques clearly carry potential risks in these older children with significant somatic involvement. The safest approach in these patients is the administration of a high inspired oxygen concentration and maintenance of spontaneous ventilation until the ainway is secured. Ideally this may be accomplished with a carefully titrated inhalation induction; however, as discussed, this may not be feasible in some cases. Other options include the use of small, carefully titrated doses of thiopentone to facilitate inhalation induction, maintaining spontaneous ventilation, as advocated by King, Jones and Bamett, ${ }^{6}$ the use of sedation combined with local anaesthesia or, as a last resort, awake intubation. Tracheostomy under local andesthesia has been reported prior to a definitive surgical procedure in a patient with the Hurler syndrome ${ }^{4}$

We used ketamine, without incident, in one patient with the Sanfilippo syndrome. However, this patient had also had no difficulties associated with several previous intravenous inductions with thiopentone and succinylcholine. Kempthome and Brown ${ }^{3}$ reported an uncomplicated ketamine anaesthetic in a nine-year-old patient with the Hurler syndrome with a history of difficult and failed intubations. They suggested that this agent may represent a useful alternative technique in such patients.

Finally, we report one patient with the Morquio syndrome, a syndrome not reported in other recently published series. These patients demonstrate profound, progressive skeletal involvement although they are usually normal, or nearly normal, intellectually. The patient in this series underwent two uneventful anaesthetics for myringotomy and insertion of drainage tubes prior to the elucidation, based on CT scan and cervical myelography, of an associated hypoplastic odontoid process and cervical spinal stenosis due to pachymeningitis cervicalis. No problems were encountered with either procedure. Cervical spine tomograms conducted several months later, when the patient became clinically symptomatic, revealed no evidence of atlanto-axial subluxation.

Several reports have documented a very high incidence of odontoid hypoplasia associated with the Morquio syndrome. ${ }^{1,8,9}$ This condition has also been reported in association with the Maroteaux-Lamy syndrome and the Hurler syndrome although the incidence is much lower in these patients.

We report no experience with patients with the Scheie syndrome, the Hurler-Scheie syndrome or the MaroteauxLamy syndrome. Experience with this latter syndrome was reported by both Kempthorne and Brown ${ }^{3}$ and $B$ aines and Keneally. ${ }^{4}$ Two case reports of the Hurler-Scheie syndrome were recently reported by Sjogren and Pedersen. ${ }^{10}$

\section{Summary}

In conclusion, we have presented our experience providing anaesthesia for nine patients with the Hurler, Hunter, Sanfilippo or Morquio syndromes, who underwent a total of 38 operative or diagnostic procedures. Problems associated with establishment and maintenance of an adequate airway are the major complications associated with anaesthesia in these patients. These problems are most prominent in those patients with significant somatic involvement, in whom inhalation induction is often difficult and intravenous agents potentially dangerous. Options are discussed for management of the induction of anaesthesia in these challenging patients.

\section{Acknowledgement}

The authors gratefully acknowledge the administrative and secretarial assistance of Mrs. M. Koen and Ms. N. Padouin in the preparation of this manuscript. 


\section{References}

I McKusick VA, Neufeld EF. The Metabolic Basis of Inherited Disease. 5th ed. Stanbury JB et al. (cds). McGraw Hill, Chapter 36, p. 751, 1983.

2 Sly W. Metabolic Control and Disease. 8th ed. Bondy PK, Rosenberg LE (eds). W.B. Saunders, Chapter 10, p. 545, 1980.

3 Kempthorne PM, Brown TKC. Anaesthesia and the mucopolysaccharidoses: a survey of techniques and problems. Anaesth Intensive Care 1983; 11: 203-7.

4 Baines $D$, Keneally $J$. Anaesthetic implications of the mucopolysaccharidoses: a fifteen-year experience in u chil dren's hospital. Anaesth Intensive Care 1983; 11: 198-202.

5 Young ID, Harper PS. Mild form of Hunter's syndrome: clinical delineation based on 31 cases. Arch Dis Child 1982; 57 : 828-36.

6 King $D H$, Jones RM, Barnett MB. Anaesthetic considerations in the mucopolysaccharidoses. Anaesthesia 1984; 39: 126-31.

7 Brosius FC III, Roberts WC. Coronary artery discase in the Hurler syndrome. Am J Cardiol 1981; 47: 649-53.

$B$ Jones AEP, Croley TF. Morquio syndrome and anesthesia. Anesthesiology 1979; 51: 261-2.

9 Lipson SJ. Dysplasia of the odontoid process in Morquio's syndrome causing quadriparesis. J Bone Joint Surg 1977; 59-A: 340-4.

10 Sjogren P, Pedersen T, Anaesthetic problems in HurlerScheie syndrome. Report of twn cases. Acta Anaesthesiol Scand 1986; 30: 484-6.

\section{Résumé}

Les patients atteints de mucopolysaccharidoses démontrent une atteinte progressive étendue de plusieurs organes et tissus pouvant avoir des implications importantes pour l'anesthésiste. Ces atteintes sont peu communes et peu d'anesthésistes soignent ces patients régulièrement mème si quelques-uns de ces paitents subissent piusieurs anesthésies afin d'anteliorer leur qualité de vie. Il y a relativement très peu d'articles dans la litterature concernant l'expérience anesthésique avec ces patients. On rapporte une étude rétrospective sur l'expérience récente du Children's Hospital of Eastern Ontario à Ottawa. Canada, sur 38 aneshésies sur neuf patients ateints de mucopolysaccharidoses spécialement les syndromes de Hunter, Hurler, Sanfilippo et Morquio. L'établissement et le maintien des voies aérienney représentent le problème le plus communément rencontré chez ces patients. L'incidence totale des problèmes reliés aux voies aériennes était de 26 pour cent. Chez les patients atteints du syndrome de Hurler ou de Hunter l'incidence des problèmes reliés aux voies aériennes était de 53 pour cent. 